\title{
Optimization of Daylight and Thermal Performance of Building Façade: A Case Study of Office Buildings in Nanjing
}

\author{
Hainan Yan ${ }^{1(\bowtie)}$, Yiting Zhang ${ }^{2}$, Sheng Liu $^{3}$, Ka Ming Cheung ${ }^{3}$, and Guohua $\mathrm{Ji}^{1(\bowtie)}$ \\ ${ }^{1}$ School of Architecture and Urban Planning, Nanjing University, Nanjing, China \\ jgh@nju.edu.cn \\ ${ }^{2}$ School of Architecture, Carnegie Mellon University, Pittsburgh, USA \\ ${ }^{3}$ School of Architecture, The Chinese University of Hong Kong, Shatin, NT, Hong Kong
}

\begin{abstract}
In China's hot summer and cold winter areas, the façade design of buildings needs to respond to a variety of performance objectives. This study focuses on the optimization of daylight and solar radiation of building façade of office buildings in Nanjing and proposes a simple and efficient method. The method mainly includes a random sampling of design models, simplified operation of daylight performance criteria and selection of optimal solution. The results show that the building façade can improve the indoor lighting uniformity and reduce the indoor illumination level compared with the unshaded reference building. Besides, the amount of solar radiation received by office buildings in summer and winter becomes more balanced with the building façade. The optimization design method of building façade proposed in this study can be of guiding significance for office buildings in Nanjing.
\end{abstract}

Keywords: Daylight · Solar radiation · Office buildings · Building façade · Parametric analysis

\section{Introduction}

Total building area in China has reached 63.487 billion $\mathrm{m}^{3}$, of which about 11.506 billion $\mathrm{m}^{3}$ are public buildings [1]. In terms of energy consumption intensity per unit area, the energy use intensity is the highest for public buildings, and has been growing. Among public buildings, office building has great energy-saving potentials, especially in the economically developed region such as the Yangtze River Delta. Building energy performance is usually affected by various factors, e.g., building envelope designs, occupants' behaviours, and heating, ventilation and air-conditioning system. Among them, almost half of the energy consumption of buildings is directly or indirectly caused by the building façade performance [2]. In recent years, architects often utilized energy efficiency design strategy to achieve net-zero energy buildings with high performance. Building façade plays an important role in the whole system of buildings to regulate the microclimate around buildings, which can reduce the energy consumption and adverse environmental impacts, see Fig. 1 [3]. 


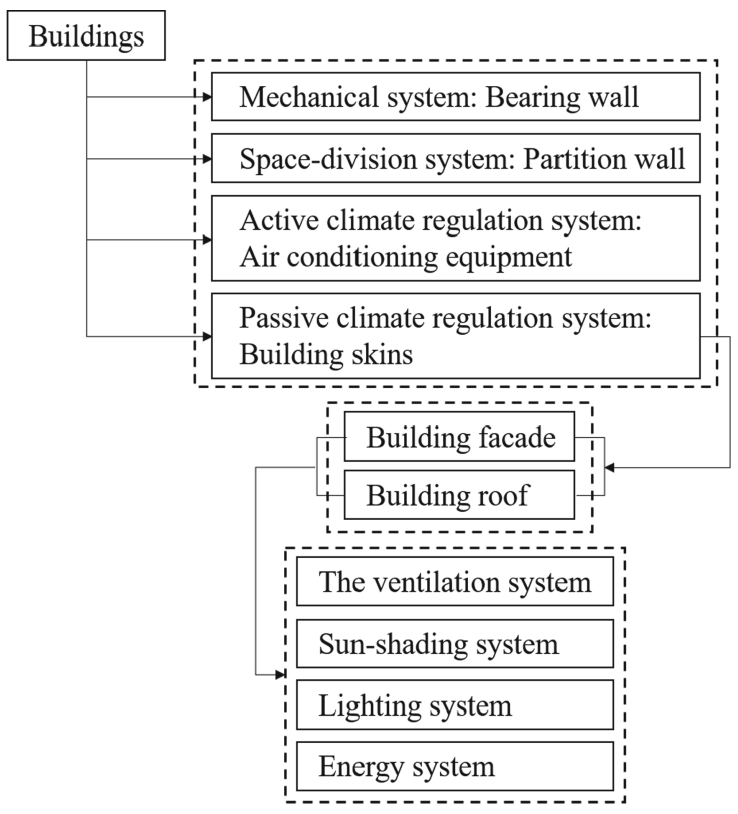

Fig. 1. A full system of the building.

With the development of technology and the demand of use, building façade have gradually separated from the structural parts. The building façade design becomes an important part of architectural design processes. The building façade design process normally has the composite and flexible characteristics. Tabadkani et al. [4] summed up the concept of the dynamic façade and adaptive façade. Many terms have been introduced, including kinetic façade, intelligent façade, interactive façade, responsive façade, and smart façade. These studies on façade mainly focused on improving indoor thermal comfort and reducing building energy consumption. For instance, Ricci et al. [5] proposed a building dynamic façade based on climate adaptability by using the parametric performance analysis platform LadybugTools. The dynamic façade is simulated and verified in different climate regions in Europe. The results showed that the system has better building energy-saving effect and indoor thermal comfort due to its dynamic and changeable characteristics. Sabry et al. [6] analyzed the optimal configuration of composite façade system with the design objective of daylighting performance of office space in hot and arid areas. Sheikh et al. [7] studied the design of adaptive bionic façade based on Oxalis. The simulation results showed that the proposed bionic façade can significantly reduce the energy consumption of high glazed buildings with the minimum reduction of visual comfort. To sum up, the method and objectives of designing building façade are diversified and multi-objective, because designing of building façade is an expression of modern architectural aesthetics and culture, and is an important way to adjust the physical environment of buildings.

In terms of research methods, the generation of flexible parametric models of building façade and finding the optimal solution of building façade with high efficiency are the two 
main concerns of related research [8,9]. However, the traditional building façade shaping and optimization process often rely on the global heuristic search algorithms, such as the genetic algorithm. Such a process makes the entire workflow time-consuming and inefficient [10]. Based on this, this study proposes the following questions in different stages of workflow:

- Is it possible to employ some design models to replace all design models for performance simulation?

- Is it possible to simplify the performance criteria?

- Is it possible to simplify the display and selection of optimal solutions? It can assist designers to make design decisions more quickly.

The above questions ultimately point to the effectiveness and efficiency of the design workflow, which is also the main content to be explored in this study.

This study aims to develop a novel parametric design method for the building façade in the context of the Yangtze River Delta region of China. First, algorithms of parametric design and shape generation are studied, and the parts that can be applied to the shape generation of building façade are summarized. Then, taking the an office building in Nanjing as a case study, this study applies this novel design method for design building façades and discusses its application on optimization of the solar thermal performance. This method enables designers to take into account the form of the building façade and its influence on the internal performance of the building at the early design stage, so as to carry out rapid scheme comparison and selection, and improve the design efficiency. In addition, the building façade generation and optimization method proposed in this study should be universal and can be applied in other types of building façade.

\section{Research Method}

The primary goal of this study is to propose an innovative modular dynamic building façade system. To that end, the Voronoi diagram and its deformation are studied. Voronoi diagram is a kind of subdivision of space plane, which is characterized by that any position in a polygon is closest to the sample points of the polygon, far away from the sample points of adjacent polygons, and each polygon contains and only contains one sample point [11]. Grasshopper is a plug-in for Rhinoceros 3D modelling software, which can integrate with many functions, such as parametric modeling and building performance analysis. In recent years, it is widely used in the field of digital architectural design. In this study, the building façade module is generated by the Grasshopper platform and its variable types and ranges are set. This study focuses on the climatic conditions of Yangtze River Delta region of China and takes the office buildings in Nanjing as an example to apply the above variable building façade. Meanwhile, the reference building was set up in this study to compare and analyze the benefits of variable building façade in terms of solar radiation and indoor lighting through simulation data. Figure 2 shows the research process and research methods of this study. 


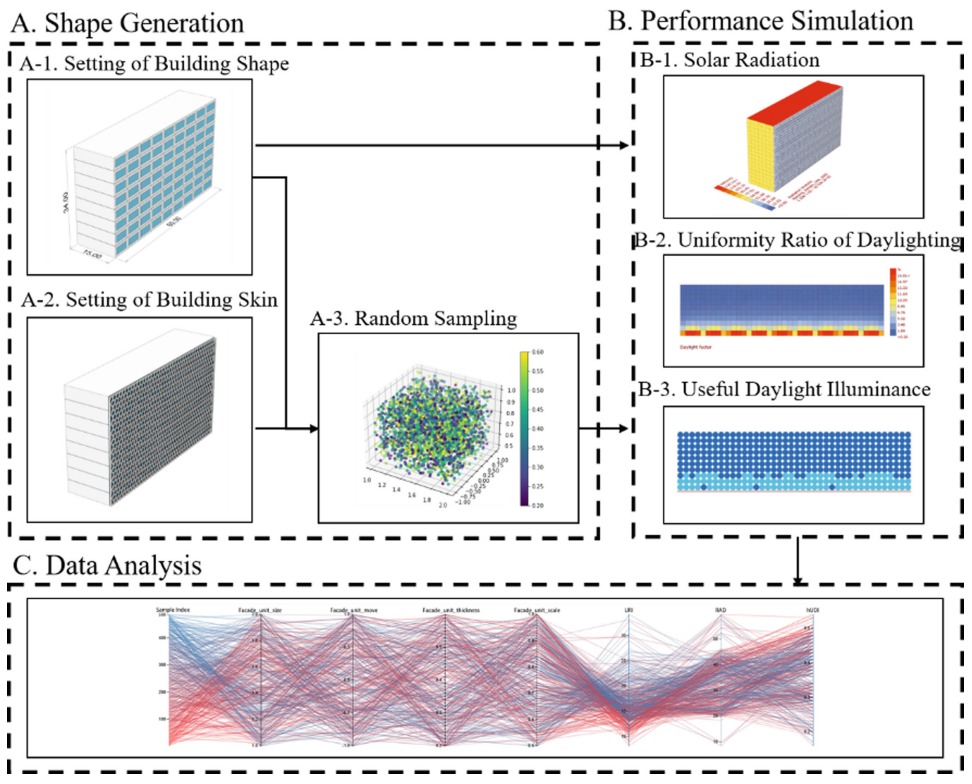

Fig. 2. Research processes and methods.

\subsection{Shape Generation}

The experimental site is set in Nanjing, in which summer is hot and winter is cold. An office building in the Gulou campus of Nanjing University is taken as an example. The office building has 8 floors, with spatial dimensions of $60 \mathrm{~m}$ (length), $15 \mathrm{~m}$ (width) and $34 \mathrm{~m}$ (clear height). Field measurement results show that the window-to-wall ratio (WWR) of this office building is about $50 \%$ (Fig. 3). The trade-offs between different design performances of office buildings in Nanjing area is complex, such as the relationship between shading and artificial lighting, the relationship between wide field of vision and personal privacy, the relationship between daylighting and glare, etc. Different from the demand of the buildings in other areas in southern China, the buildings in Nanjing need shading in summer and lighting in winter, so architects need to conduct performance analysis to guide the shading design.

For the office space, the position of the staff is usually fixed, so the indoor light and environmental requirements are higher than that of other building types. Building façade plays an essential role in providing shading or sufficient lighting for the interior. Based on this consideration, this study considers applying Voronoi form to the south façade design of office space. Four types of changes are carried out in the form of façades, including the deformation of façade units, the scaling of façade units, the thickness of façade units and the hole scaling. These changes can change the indoor lighting and thermal environment (Fig. 4). In the process of building façade sampling and performance simulation, it is necessary to constrain the variable range of the parametric model of building façade and give the change interval. According to the actual façade design and construction experience, it is appropriate to set the façade unit size between $1.0 \mathrm{~m}$ and $2.0 \mathrm{~m}$, and the maximum displacement distance of the façade unit is $1 \mathrm{~m}$ in the horizontal direction. In 

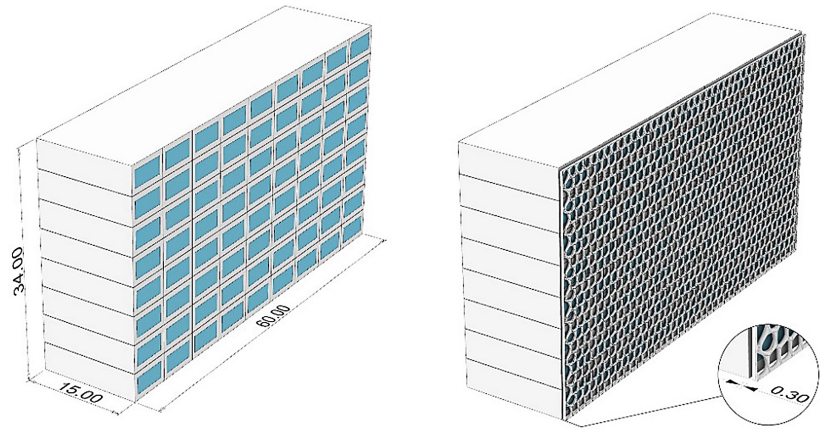

Fig. 3. The setting of office building form and size.

addition, due to the high requirements for natural lighting for offices, the proportion of windows in the façade should not be too small, and the change range is determined to be between 0.5 and 1.0. The thickness change range of building façades is set between $0.2 \mathrm{~m}$ and $0.6 \mathrm{~m}$. To sum up, the variable parameters of building façade are summarized in Table 1.

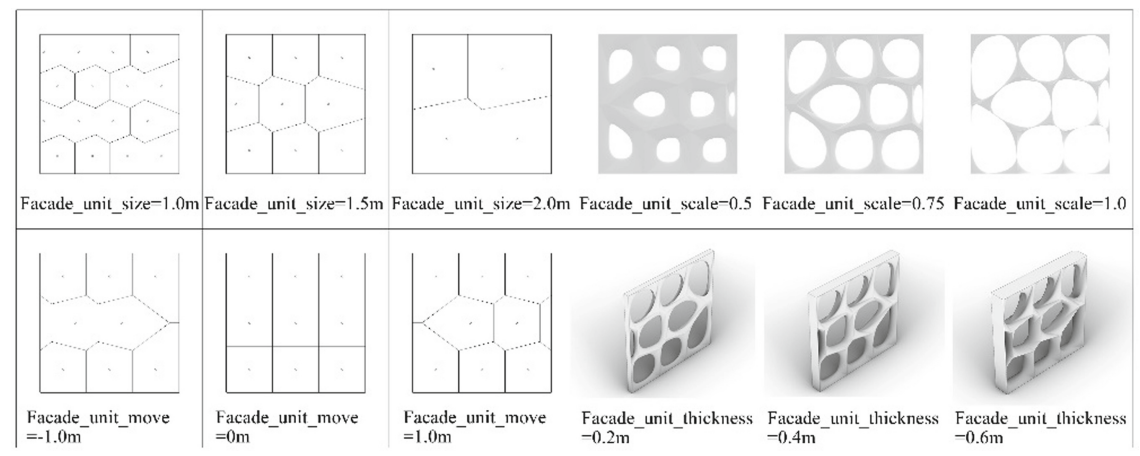

Fig. 4. Analysis on the formation of building façade.

\subsection{Performance Simulation}

The main purpose of this part is to analyze the influence of the parameterized variable model of the building façade proposed above on solar radiation and natural lighting. To this purpose, Honeybee environmental plug-in for Grasshopper was used to investigate the daylight performance of each building façade configuration. Honeybee provides the advanced grid-based daylighting mode in which it allows the designer to control façades according to the amount of light on the elevated task area with $75 \mathrm{~cm}$ height in this research. In addition, the Ladybug plug-in for Grasshopper is used to calculate the solar radiation received by the south façade of the building in winter and summer. 
Table 1. Variable intervals and variable types of building façade.

\begin{tabular}{l|l|l}
\hline Variable name & Variable interval & Variable type \\
\hline Façade_unit_size & $1.0-2.0$ & $\begin{array}{l}\text { Continuous } \\
\text { variable }\end{array}$ \\
\hline Façade_unit_scale & $0.5-1.0$ & $\begin{array}{l}\text { Continuous } \\
\text { variable }\end{array}$ \\
\hline Façade_unit_move & $-1.0-1.0$ & $\begin{array}{l}\text { Continuous } \\
\text { variable }\end{array}$ \\
\hline Façade_unit_thickness & $0.2-0.6$ & $\begin{array}{l}\text { Continuous } \\
\text { variable }\end{array}$ \\
\hline
\end{tabular}

This study selects the lighting uniformity based on the static light environment evaluation and the indoor lighting level at a specific time as factors. The reason is that the method proposed by this study is mainly used in the design phase, and pays more attention to the efficiency of performance simulation. Compared with the dynamic environment simulation, the static light environment simulation is more efficient in saving time. In addition, the solar radiation received by office buildings in winter and summer is considered in this study. The setting of performance criteria is shown in Table 2.

In order to verify the simulation results, the initial office building without a building façade is set as the reference building. The reference building also needs to be simulated and calculated independently to obtain the reasonable results.

Table 2. Performance criteria setting.

\begin{tabular}{l|l|l}
\hline Performance criteria & Unit & Object type \\
\hline Uniformity ratio of daylight (URD) & $\%$ & Max \\
\hline Hourly useful daylight illuminance (hUDI) & $\%$ & Max \\
\hline $\begin{array}{l}\text { Difference in solar radiation heat gain between winter and summer } \\
\text { (RAD) }\end{array}$ & $\mathrm{kWh} / \mathrm{m}^{2}$ & Min \\
\hline
\end{tabular}

- URD: The daylight factor (DF) is one of most commonly used building daylighting evaluation indicators $[12,13]$. It is easy to calculate but cannot represent various weather brightness changes. Basing on the reference to the "Standard for Daylighting Design of Buildings" published by the Ministry of Housing and Urban-Rural Development of China, this study sets the uniformity ratio of daylight (URD) to evaluate the distribution of indoor illuminance in buildings. URD is the ratio of the lowest to the average of the daylight factor (DF) on the reference plane. The optimization objective is the maximum of URD, and the calculation of URD is as follows:

$$
\mathrm{URD}=\mathrm{DF}_{\min } / \mathrm{DF}_{\mathrm{avg}}
$$


- hUDI: The useful daylight illuminance (UDI) is designed to aid the interpretation of climate-based analyses of daylight illuminance levels that are founded on hourly meteorological data for a full year period [14]. However, capturing UDI values in the performance simulation process can be time-consuming. To comprehensively evaluate the indoor lighting conditions at different times of a year, four hours are set for the simulation of building façades: 21st of March, June, September and December at 12 P.M., which are represented respectively as Hour of the Year (HOY): 1908, 4116,6324 and 8508 [15]. The hUDI is the area proportion of the illuminance in the range of 3001x-20001x on the reference plane at a specific moment, and its optimization objective is the maximum of hUDI.

- RAD: For cold winter and hot summer areas, the summer solar radiation is generally harmful for indoor thermal comfort, while the winter solar radiation is beneficial. In this study, the solar radiation of the south façade of the building in June (summer) and December (winter) was calculated and the difference between them was calculated. The optimization objective is the minimum of RAD, and the calculation of RAD is as follows:

$$
\text { RAD }=\text { Radiation }_{\text {summer }}-\text { Radiation }_{\text {winter }}
$$

\subsection{Data Analysis and Visualization}

- Random sampling: In this paper, the variables of building façade will form a huge sample set through the combination. If all the samples are analyzed, it is very timeconsuming and unnecessary. Sampling is to reasonably extract a certain amount of samples from the whole sample set for performance simulation and analysis, and it has a small impact on the results. Therefore, sampling technology is very important to the accuracy and efficiency of the research process. In this paper, the Monte Carlo simulation method is used for random sampling to obtain 500 variable combinations (samples) of building façade.

- Data visualization: In this study, the DesignExplorer online platform was used to plot 500 random samples, which were used to show the variable combination and simulation data [16]. To mine the performance simulation data more accurately, the box plot is used to analyze the optimization potential of building façade. The optimization potential analysis of building façade can directly reflect the improvement degree of certain performance criteria, which can assist architects to make optimization decisions.

\section{Result Analysis}

This research utilizes an interactive parallel coordinate system to filter the target performance criteria of 500 random samples, then obtains several optimal variable combinations. After the numerical filtering of each performance, some non-optimal samples will be eliminated, and the optimal solution of building façade variable combination will be retained. As shown in Fig. 5a-d, the left side of each figure is the value of building façade variability, and the right side is the performance criteria. According to Fig. 6(a), the numerical range of each performance criteria can be preliminarily determined. Furthermore, the optimal filtering interval of URD is set to $20 \%-30 \%$, the optimal filtering 


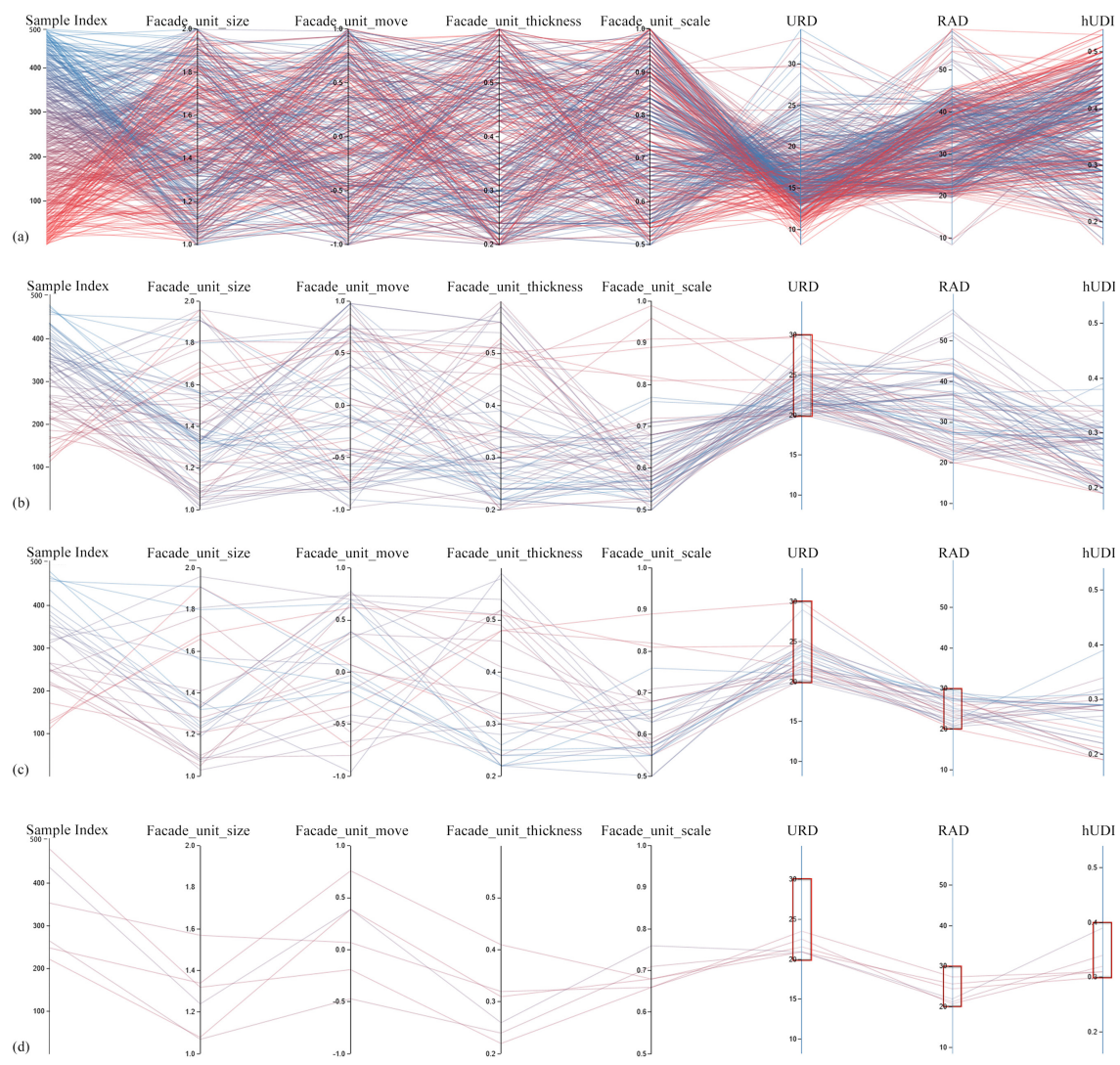

Fig. 5. Simulation results of daylight and thermal performance of office buildings; full spectrum of the results for 500 iterations (a), best performing design scenarios for the URD (b), best performing design scenarios for the URD \& RAD (c) and best performing design scenarios for the URD \& RAD \& hUDI (d).

interval of RAD is set to $20 \mathrm{kWh} / \mathrm{m}^{2}-30 \mathrm{kWh} / \mathrm{m}^{2}$, and the optimal filtering interval of hUDI is set to $30 \%-40 \%$. Finally, six sets of optimized solutions that meet the filtering requirements are obtained.

The process above based on 500 random samples can significantly reduce the number of samples, and produce several optimal solutions that meet the requirements. Though this method faces the risk of losing more optimal solutions, it can be alleviated by increasing the number of samples appropriately. Compared with the genetic algorithm optimization method, this study can get the optimal solution more efficiently and quickly. The simplification of the design process makes it easier for designers to understand and adopt.

Figure 6 (left) illustrates that the overall distribution of hUDI value is between $16.38 \%$ and $54.83 \%$, with an average of $39.05 \%$. Compared with the reference building $(50.25 \%)$, the addition of building façade makes the indoor lighting level decline. Meanwhile, Fig. 6 (middle) shows that the overall distribution of URD value is between 

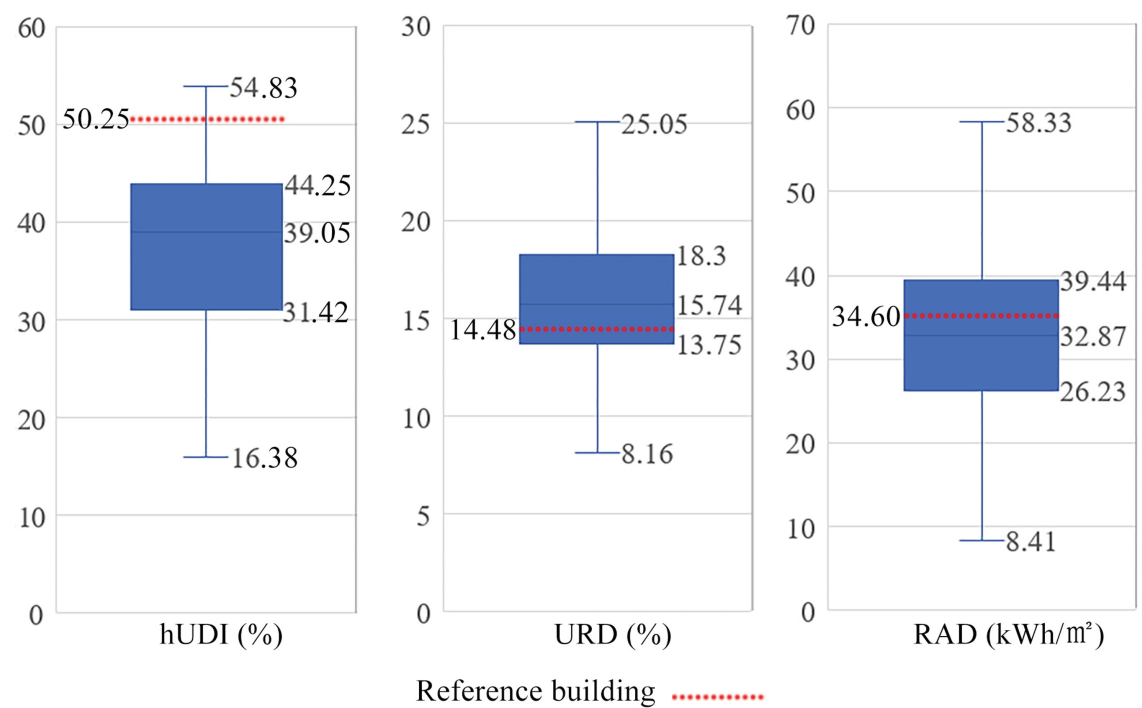

Fig. 6. Analysis on the optimization potential of daylight and thermal performance of building façade: optimization potential analysis of hUDI (left), optimization potential analysis of URD (middle) and optimization potential analysis of RAD (right).

$8.16 \%$ and $25.05 \%$, with an average of $15.04 \%$. In contrast, the URD value of the reference building is slightly lower $(14.48 \%)$. Due to the ability to block the glare near the window and reflecting more light into the room, building façade components can improve indoor lighting uniformity. According to the box chart of solar radiation data on the south face of the building (Fig. 6, right), RAD values are generally distributed between $8.41 \mathrm{kWh} / \mathrm{m}^{2}$ and $58.33 \mathrm{kWh} / \mathrm{m}^{2}$, with an average of $32.87 \mathrm{kWh} / \mathrm{m}^{2}$. Compared with the reference building $\left(34.60 \mathrm{kWh} / \mathrm{m}^{2}\right)$, the difference of solar radiation heat gain in summer and winter has a certain optimization potential. In general, the façade added to the south face of the building reduces the level of indoor lighting, but it improves the uniformity of indoor lighting. In addition, the amount of solar radiation received by office buildings in summer and winter becomes more balanced than the reference building.

\section{Conclusion}

The design objectives of building façade are often multifaceted, involving lighting, solar radiation, building energy consumption and vision, etc. This research focuses on the optimization of office building façade for daylighting and solar radiation. The innovative design process of building façade in this study can be applied to designing the south face of office buildings in Nanjing. The originality and value of this research method are as follows: 
- The Monte Carlo random simulation method is used to sample the design model randomly, which effectively reduces the workload of subsequent performance simulation and optimization solution selection.

- In this study, the UDI is simplified for the indoor illumination index. The index of hUDI was used to represent the proportion of effective lighting (3001x-20001x) area at the same time point in four seasons.

- Compared with using genetic algorithm for global search and optimization, this study combined with Designexplore to intuitively display the simulation results and set the performance target optimization interval, which is more conducive to the designer's scheme selection and design decision.

This study only proposes a specific design process and does not consider the face of other directions of the building. The research on the performance of building façade in building energy consumption or indoor thermal comfort is also missing. In further research, it is necessary to have more diverse building façade forms and a more comprehensive process on building performance evaluation and optimization.

Funding. This research was funded by the Opening Fund of Key Laboratory of Interactive Media Design and Equipment Service Innovation, Ministry of Culture and Tourism (Project Number: 20204).

\section{References}

1. Lin, L., Liu, X., Zhang, T., Liu, X.: Energy consumption index and evaluation method of public traffic buildings in China. Sustain. Cities Soc. 57, 102-132 (2020)

2. Hasselaar, B.L.H.: Climate Adaptive Skins: towards the new energy-efficient façade. In: 1st International Conference on Management of Natural Resources, Sustainable Development and Ecological Hazards, Ravage of the PLANET 2006, RAV06, pp. 351-360 (2006)

3. Velikov, K., Thün, G.: Responsive building envelopes: characteristics and evolving paradigms. In: Trubiano, F. (ed.) Design and Construction of High Performance Homes, pp. 75-92 (2013)

4. Tabadkani, A., Roetzel, A., Li, H.X., Tsangrassoulis, A.: Design approaches and typologies of adaptive façades: a review. Autom. Constr. 121, 103450 (2021)

5. Ricci, A., Ponzio, C., Fabbri, K., Gaspari, J., Naboni, E.: Development of a self-sufficient dynamic façade within the context of climate change. Archit. Sci. Rev. 64, 87-97 (2021)

6. Sabry, S.M., El-Ela, M.M.A., Farag, M.A.: Development of form proportions configurations in office building skins in order to improve daylight levels using "Parametric Design Methods". J. Am. Sci. 11 (2015)

7. Sheikh, W.T., Asghar, Q.: Adaptive biomimetic façades: enhancing energy efficiency of highly glazed buildings. Front. Archit. Res. 8, 319-331 (2019)

8. Kim, H., Clayton, M.J.: A multi-objective optimization approach for climate-adaptive building envelope design using parametric behavior maps. Build. Environ. 185, 107292 (2020)

9. Pan, W., Turrin, M., Louter, C., Sariyildiz, S., Sun, Y.: Integrating multi-functional space and long-span structure in the early design stage of indoor sports arenas by using parametric modelling and multi-objective optimization. J. Build. Eng. 22, 464-485 (2019)

10. Zhang, L., Zhang, L., Wang, Y.: Shape optimization of free-form buildings based on solar radiation gain and space efficiency using a multi-objective genetic algorithm in the severe cold zones of China. Sol. Energy 132, 38-50 (2016) 
11. Sugihara, K.: Voronoi diagrams, Chap. 18. In: Farin, G., Hoschek, J., Kim, M.-S. (eds.) BT-H of CAGD, pp. 429-450. North-Holland, Amsterdam (2002)

12. Calcagni, B., Paroncini, M.: Daylight factor prediction in atria building designs. Sol. Energy 76, 669-682 (2004)

13. Ibarra, D., Reinhart, C.F.: Daylight factor simulations-how close do simulation beginners 'really' get. In: Building simulation, p. 203 (2009)

14. Nabil, A., Mardaljevic, J.: Useful daylight illuminances: a replacement for daylight factors. Energy Build. 38, 905-913 (2006)

15. Tabadkani, A., Shoubi, M.V., Soflaei, F., Banihashemi, S.: Integrated parametric design of adaptive façades for user's visual comfort. Autom. Constr. 106, 102857 (2019)

16. Natanian, J., Wortmann, T.: Simplified evaluation metrics for generative energy-driven urban design: a morphological study of residential blocks in Tel Aviv. Energy Build. 240, 110916 (2021)

Open Access This chapter is licensed under the terms of the Creative Commons Attribution 4.0 International License (http://creativecommons.org/licenses/by/4.0/), which permits use, sharing, adaptation, distribution and reproduction in any medium or format, as long as you give appropriate credit to the original author(s) and the source, provide a link to the Creative Commons license and indicate if changes were made.

The images or other third party material in this chapter are included in the chapter's Creative Commons license, unless indicated otherwise in a credit line to the material. If material is not included in the chapter's Creative Commons license and your intended use is not permitted by statutory regulation or exceeds the permitted use, you will need to obtain permission directly from the copyright holder.

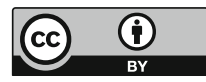

